\title{
Vibration Response and Evaluation Method of High-Speed Tracked Vehicles Driving Off-Road
}

\author{
Xin-yong Qiao $\mathbb{D},{ }^{1}$ Ying Jin $\mathbb{D},{ }^{1}$ and Cheng Gu $\mathbb{D}^{2}$ \\ ${ }^{1}$ Vehicle Engineering Department, Army Academy of Armored Forces, Beijing 100072, China \\ ${ }^{2}$ Beijing Special Engineering Design and Research Institute, Beijing 100028, China \\ Correspondence should be addressed to Ying Jin; nancy.jin-ying@163.com
}

Received 21 October 2021; Revised 6 December 2021; Accepted 24 December 2021; Published 3 February 2022

Academic Editor: Vasudevan Rajamohan

Copyright $\odot 2022$ Xin-yong Qiao et al. This is an open access article distributed under the Creative Commons Attribution License, which permits unrestricted use, distribution, and reproduction in any medium, provided the original work is properly cited.

In the stage of vehicle demonstration and development, equipment finalization test, and equipment service, an important role is played by the mobility prediction and evaluation method of tracked vehicles under complex road conditions, in which vehicle vibration response evaluation is the main content of off-road mobility prediction and evaluation. In this paper, based on the principle of multibody dynamics, a high-speed tracked vehicle action system model was established by using the simulation analysis method. The vibration response of the vehicle on uneven pavement was evaluated from four aspects: driver comfort, driver absorbed power, occupant handling efficiency, and suspension dynamic travel. Simultaneously, the shock vibration peak value was utilized to evaluate the vibration response of the vehicle during obstacle crossing. Three fitting methods, namely polynomial response surface, Kriging method, and radial basis function neural network, were used to establish approximate models between the design variables and the objective function, respectively. The pros and cons of each approximate model were analyzed by comparing the approximate errors between the predicted values of the fitting model and the actual response values of the simulation model. The results of this paper are of reference significance for the prediction and evaluation of the off-road mobility of high-speed tracked vehicles.

\section{Introduction}

The off-road mobility of high-speed tracked vehicles is a comprehensive manifestation of vehicle dynamics, flexibility, passability, and comfort. Especially, the driving environment of military high-speed tracked vehicles is relatively harsh. The mobility of vehicles is seriously affected by the strong turbulence caused by the uneven pavement and the vibration shock caused by the surface obstacles. In the wake of the increase of vehicle speed, the frequency and intensity of vibration on the human body will inevitably increase. In this case, the only response that the driver can take is to reduce the speed, demonstrating that vibration shock limits the increase in off-road driving speed $[1,2]$.

Under the condition of satisfying dynamic performance and passability, the tolerance limit of occupant and vehicle body to vehicle vibration response is the principal factor that determines the speed of tracked vehicle on uneven pavement and obstacle pavement. Since the tracked vehicle is subjected to continuous vibration for a long time when driving on uneven pavement, the power spectrum method is usually used to analyze the influence of vibration on occupants and vehicle body, and the vibration response can be evaluated from the aspects of vehicle ride comfort, suspension system reliability, and occupant handling stability. When a vehicle encounters an obstacle, the rigid contact between the front end of the vehicle body and the edge of the obstacle will produce a large short-term shock vibration, and the shock strength is usually evaluated by the maximum acceleration peak rather than the root mean square (RMS) value. For example, the index "obstacle-crossing rated vehicle speed" was proposed by the US Army on the basis of a large number of tests, and the performance of tactical wheeled vehicles to quickly pass obstacles was assessed according to the size of vertical acceleration $[3,4]$. 
Vehicle dynamics modeling, as an important technical means to analyze the vibration response of vehicles, can also be used to simulate the process of vehicle crossing obstacles. It is the basic work and primary method for vehicle mobility evaluation. The shock and vibration analysis module $[5,6]$ was taken as an example, which is the core content of dynamic prediction in the US military mobility model AMM75 , and was later improved and used in the NATO standard mobility model. A two-dimensional model of tracked vehicles was established by Dhir and Shankhala. to predict the ride comfort of vehicles [7]. The kinematics equation of tracked vehicles was established by Marcello C. with the coordinate simplification method, and the vibration characteristics of tracked vehicles were analyzed [8, 9]. A dynamic model of the tracked vehicle system was established by Scholar and Perkins, and the method of vehicle vibration response analysis was studied based on the continuous elastomeric track $[10,11]$.

Usually, the dynamic models did not consider the vibration characteristics of track and the interaction of track and vehicle. A multibody dynamic model has more than 1,000 degrees of freedom, so it is important to consider the impact of track shoes on the vehicle vibration. In this paper, a high-speed tracked vehicle action system model considering the complicated interactions of track shoes was established based on the principle of multibody dynamics. By virtue of simulation calculation, the vibration response of vehicles in off-road driving was analyzed, and an approximate model of vibration response was established. Several related concepts are explained below.

1.1. Driver Ride Comfort. When tracked vehicles are excited by road undulations, complex random vibrations will be generated by the vehicle system. Since the driver's position is farthest from the longitudinal centerline of the vehicle, the vertical vibration and pitching vibration experienced by the driver are both more severe than other occupants. In order to evaluate the ride comfort of the driver, the vibration response of the driver in all directions should be considered.

In the early 1970s, the International Standard Organization formulated the international standard ISO2631 [12] to specify the vibration response limit of the human body to withstand multi-input multi-axial vibration and long-term random vibration.

Based on the total weighted value method proposed by ISO2631-1, the root mean square values of the three-way acceleration in $201 / 3$ frequency bands were calculated, and the RMS values of the total weighted acceleration were obtained by calculating the vector sum according to different weighting coefficients. With this method, the sensitivity of the human body to vibration of different frequencies was considered, and the influence of vibration in the frequency range from 1 to $80 \mathrm{~Hz}$ on the human body was comprehensively reflected, as shown in Table 1 . It can be seen that when the RMS value of the weighted acceleration at the driver's seat is greater than about $1 \mathrm{~m} / \mathrm{s}^{2}$, the driver will feel uncomfortable. Therefore, $1 \mathrm{~m} / \mathrm{s}^{2}$ is used as the threshold value of the evaluation index of ride comfort.
TABLE 1: Comfort reactions to vibration environments.

\begin{tabular}{lc}
\hline RMS of total weighted acceleration & Reactions \\
\hline Less than $0.315 \mathrm{~m} / \mathrm{s}^{2}$ & Not uncomfortable \\
$0.315 \mathrm{~m} / \mathrm{s}^{2}$ to $0.63 \mathrm{~m} / \mathrm{s}^{2}$ & A little uncomfortable \\
$0.5 \mathrm{~m} / \mathrm{s}^{2}$ to $1 \mathrm{~m} / \mathrm{s}^{2}$ & Fairly uncomfortable \\
$0.8 \mathrm{~m} / \mathrm{s}^{2}$ to $1.6 \mathrm{~m} / \mathrm{s}^{2}$ & Uncomfortable \\
$1.25 \mathrm{~m} / \mathrm{s}^{2}$ to $2.5 \mathrm{~m} / \mathrm{s}^{2}$ & Very uncomfortable \\
Greater than $2 \mathrm{~m} / \mathrm{s}^{2}$ & Extremely uncomfortable \\
\hline
\end{tabular}

1.2. Driver Absorbed Power. Based on the off-road driving characteristics of highly maneuverable tracked vehicles, an absorbable power standard was proposed by the U.S. Army Tank-Automotive Command to evaluate the shock vibration of occupants [13]. During the driving of the vehicle, the human body is subjected to vibrations in three directions, and the rate of change of the vibration energy over time is the absorbed power. The formula for calculating absorbed power via acceleration response is as follows:

$$
P_{v}=\sum_{i=1}^{n} K_{i} a_{i}^{2},
$$

where $P_{v}$ is the average absorbed power; $K_{i}$ is the frequency absorption coefficient at the $i$ th frequency; $a_{i}$ is the vibration acceleration at the $i$ th frequency.

In order to facilitate the calculation, the absorbed power $P_{v}$ was converted to the frequency domain, and its calculation formula is as follows:

$$
P_{v}=1035.2444 \sum_{i=1}^{n} K_{i} G_{i}(f),
$$

where $G_{i}(f)$ is the self-power spectrum value of the vibration acceleration at the $i$ th frequency.

It is found that there is an approximate relationship between the absorbed power standard and the RMS value of weighted acceleration specified in the international standard ISO2631 [2]:

$$
P_{v}=0.5591 a_{z w}^{2}+1.8265 a_{z w}-0.29989
$$

where $a_{z w}$ is the RMS value of the weighted vertical acceleration.

It is considered in a study by the U.S. Army that the limit of the power absorbed by the human body is $6 \mathrm{~W}$, beyond which the human body can only concentrate on the handrail and cannot work properly. According to the empirical formula, when the absorbed power of the driver is $6 \mathrm{~W}$, if the corresponding limit RMS of the vertical weighted acceleration is about $2.07 \mathrm{~m} / \mathrm{s}^{2}$, then the threshold value of the RMS value $a_{z w}$ of the vertical weighted acceleration is set as $a_{z w} / 3=0.69 \mathrm{~m} / \mathrm{s}^{2}$.

1.3. Suspension Dynamic Travel. "Suspension breakdown" means that the suspension dynamic travel of a tracked vehicle exceeds the designed dynamic travel, resulting in a rigid shock between the balance elbow and the travel limiter. In case of a "suspension breakdown" phenomenon, severe vibration shock will be produced, which has serious adverse 
effects on the occupants and balance elbow and other moving parts. When a tracked vehicle is running on uneven pavements, the higher the speed, the greater the possibility of "suspension breakdown." The suspension dynamic travel reflects the superimposed effect of the vertical vibration of the vertical body and road wheels as well as the pitch vibration of the vertical body. The first load wheel is subjected to the most severe shock vibration and is most affected by the body pitching vibration compared to other load wheels. In view of this, the suspension dynamic travel was calculated by the relative vertical displacement $Z_{R}$ between the first road wheel and the coordinate points of the vehicle body directly above the road wheel [14]:

$$
Z_{R}=0.038851 \gamma_{v}+Z_{v}-Z_{r}-0.607,
$$

where $\Upsilon_{v}$ is the pitch angle displacement of the vehicle; $Z_{v}$ is the vertical displacement of the centroid of the vehicle; and $Z_{r}$ is the vertical displacement of the road wheels.

The suspension dynamic travel of the vehicle during driving is expressed as the RMS of the vertical displacement difference between the road wheels and the vehicle body, which is expressed as follows:

$$
Z_{r w}=\left[\int_{0.5}^{80} G_{r w}(f) \mathrm{d} f\right]^{1 / 2},
$$

where $G_{r w}(f)$ is the power spectral density of the relative displacement between the road wheel and the vehicle body.

Based on the design index of high-mobility tracked vehicles, the design dynamic travel of the vehicle is set as $\left[f_{d}\right]=0.36 \mathrm{~m}$. In the actual driving process, the threshold value of the RMS value of the dynamic travel of the first load wheel should be $Z_{r w} \leq\left[f_{d}\right] / 3=0.12 \mathrm{~m}$ so as to minimize the probability of "suspension breakdown."

1.4. Occupant Handling Efficiency. During the running of the vehicle, the vibration caused by the undulation of the pavement leads to the decrease of the handling efficiency of the commander and the gunner. In this way, the sighting operation is difficult to complete, which seriously affects the shooting accuracy and even makes it impossible to shoot. The main influencing factors are the vibrations at the three typical components of the gunner's seat, console, and scope. The RMS value of the total weighted acceleration at the gunner's seat is usually used as the evaluation index of the occupant handling efficiency. When the RMS value of the total weighted acceleration at the gunner's seat reaches $0.75 \mathrm{~m} / \mathrm{s}^{2}$, the normal sight is difficult to be carried out [15], which is taken as the threshold value to limit the occupant handling efficiency.

1.5. Peak Value of Shock Vibration When Crossing Obstacles. When a high-speed tracked vehicle encounters rigid geometric obstacles such as vertical walls and ditches, the shock vibration generated by the collision between the vehicle and the obstacle during the obstacle crossing process will cause a large change in the vehicle's attitude in a short time. Since the shock time is relatively short, the power spectrum method is not suitable for evaluation. Usually, the vertical acceleration of the occupant's sitting posture is used as the vibration response index to evaluate the shock strength.

According to the speed limit standard proposed in the U.S. military AMM-75 model, the maximum peak vertical acceleration at the driver's seat after $30 \mathrm{~Hz}$ low-pass filtering does not exceed $25 \mathrm{~m} / \mathrm{s}^{2}$ during the vehicle's obstacle crossing process.

1.6. Coefficient of Determination. In this paper, the coefficient of determination $R^{2}$ was used to judge the fitting accuracy of the model in the $R^{2}$ test, and the calculation formula is

$$
R^{2}=1-\frac{\sum_{i=1}^{n}\left(y_{i}-\widehat{y}_{i}\right)^{2}}{\sum_{i=1}^{n}\left(y_{i}-\hat{y}\right)^{2}}
$$

where $\hat{y}_{i}$ is the predicted value of the sample point, $y$ is the actual response value of the sample point, $\bar{y}$ is the mean value of the actual value, and $n$ is the number of sample points selected to test the fitting accuracy. The value of $R^{2}$ is between $[0,1]$, and its numerical value represents the degree of proximity between the predicted value and the true value. Generally, the $R^{2}$ of the approximate model is greater than 0.9 to meet the accuracy requirements.

1.7. Relative Root Mean Square Error. In this paper, the relative root mean squared error (RMSE) test was used to evaluate the fitting accuracy of the approximate model, and its calculation formula is as follows:

$$
\operatorname{RMSE}=\frac{1}{n \bar{y}} \sqrt{\sum_{i=1}^{n}\left(y_{i}-\hat{y}_{i}\right)^{2}} .
$$

The size of RMSE reflects the fitting accuracy of the approximate model, and there is no specific numerical requirement. In general, depending on the situation, the lower the RMSE value, the better the fitting accuracy.

\section{Dynamic Modeling of the Action System of High-Speed Tracked Vehicles}

2.1. System Topology. The main function of the dynamic model of a high-speed tracked vehicle is to reflect the real vehicle-ground interaction relationship so as to obtain the shock vibration response characteristics of the vehicle. As a result, a dynamic model of the action system that meets the accuracy requirements needs to be established. The action system mainly includes a track propulsion system and a suspension system. The complete track model is composed of 231 rigid bodies with a total of 1,182 degrees of freedom. Based on the connection relationship between the components of the tracked vehicle, the topology relationship of the complete track model is described as shown in Figure 1, and Tables 2 and 3, respectively. 


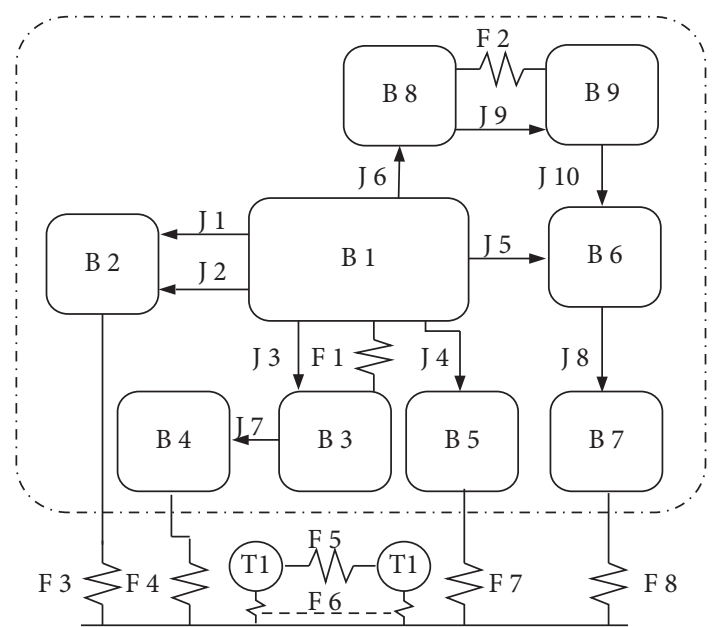

Figure 1: Topology of the complete track model.

TABLe 2: Part list of tracked vehicle action system model.

\begin{tabular}{lccccc}
\hline No. & Name & Number & No. & Name & Number \\
\hline B1 & Vehicle body & 1 & B6 & Crank arm & 2 \\
B2 & Driving wheel & 2 & B7 & Inducer & 2 \\
B3 & Balance elbow & 12 & B8 & Sliding column & 2 \\
B4 & Road wheel & 12 & B9 & Sleeve & 2 \\
B5 & Towing wheel & 6 & T1 & Flexible track & 22 \\
\hline
\end{tabular}

TABle 3: Constraint table of tracked vehicle action system model.

\begin{tabular}{lccc}
\hline No. & Name & No. & Name \\
\hline J1-J4 & Revolute joint & F2 & Spring damping torque \\
J5 & Ball joint & F3 & Spring damping force \\
J6-J7 & Revolute joint & F4 & Cylindrical joint \\
J8 & Translational joint & F5 & Contact force \\
J9 & Cylindrical joint & F6 & Contact force \\
J10 & Axis parallel constraint & F7 & Bushing force \\
F1 & Driving torque & F8 & Contact force \\
\hline
\end{tabular}

2.2. Description of Constraints in the System. In this paper, the Cartesian generalized coordinate method [16] in the multibody dynamics modeling theory was used to describe the position and attitude of the component, namely,

$$
q^{T}=[x y z \Psi \theta \varphi]
$$

where $x, y$, and $z$ are the coordinates of the centroid in the Cartesian coordinate system; $\Psi, \theta$, and $\varphi$ are the Euler angles of the centroid coordinates.

It can be seen from Tables 2 and 3 that the built model describes the kinematic relationship between adjacent objects via four types of ideal constraints: revolute joint, ball joint, translational joint, and cylindrical joint, as shown in Figure 2. Among them, the revolute joint restricts the 3-way relative translation and the 2 -way relative rotation between the adjacent parts, the ball joint restricts the 3-way relative translation between the adjacent parts, the translational joint restricts the 2 -way relative translation and the 3 -way relative rotation between the adjacent parts, and the cylindrical joint

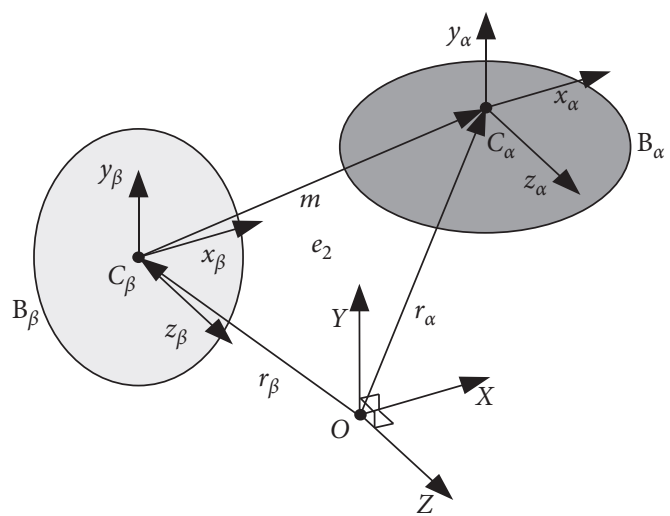

Figure 2: Kinematic relationship between rigid bodies in the generalized coordinate system.

restricts the 2 -way relative translation and 2 -way relative rotation between adjacent parts.

Taking the largest number of rotating pairs in the model as an example, the displacement constraint equation can be expressed as

$$
\left\{\begin{array}{l}
x_{\alpha \beta}=y_{\alpha \beta}=z_{\alpha \beta}, \\
\sin \theta_{\alpha \beta} \sin \varphi_{\alpha \beta}=0, \\
\sin \theta_{\alpha \beta} \cos \varphi_{\alpha \beta}=0,
\end{array}\right.
$$

where $x_{\alpha \beta}, y_{\alpha \beta}$, and $z_{\alpha \beta}$ are the displacement components of the component in the three directions; $\psi_{\alpha \beta}, \theta_{\alpha \beta}$, and $\varphi_{\alpha \beta}$ are the Euler angles of the component $B_{\alpha}$ relative to the component $B_{\beta}$.

\subsection{Description of Force Elements in the System}

2.3.1. Force Element in the Suspension System. The suspension device of the built model was simplified as a swing balance elbow and a rotating spring damper, as shown in Figure 3. The force element between the balance elbow and the vehicle body was described by the spring damping torque.

The equivalent spring moment of the balance elbow is

$$
T_{k}=k_{T}\left(\alpha-\alpha_{0}\right) \text {, }
$$

where $\alpha_{0}$ is the initial installation angle of the balance elbow.

The torsional stiffness coefficient $k_{T}$ can be calculated by the following formula:

$$
k_{T}=\frac{\pi d^{4} G}{32 L}
$$

where $d$ is the equivalent diameter of the torsion bar; $L$ is the equivalent length of the torsion bar; $G$ is the shear modulus of the torsion bar.

The equivalent damping torque of the simplified shock absorber is

$$
T_{c}=c_{T} \dot{\alpha},
$$




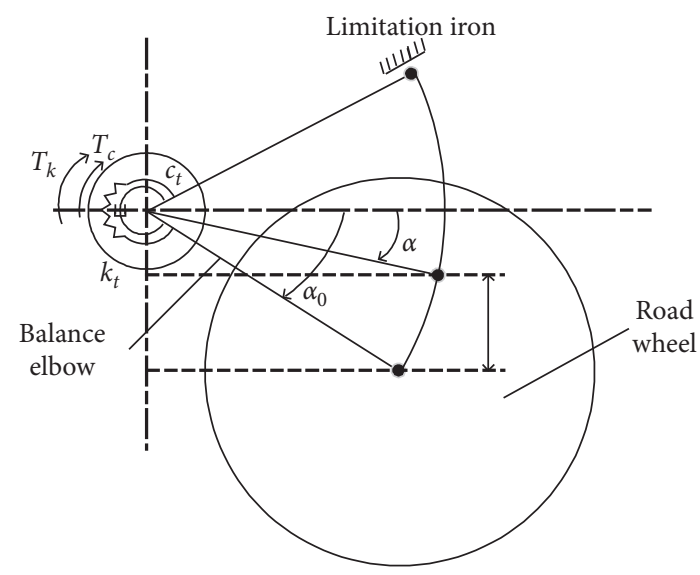

FIGURE 3: Simplified schematic diagram of suspension system.

where $c_{T}$ is the equivalent damping coefficient; $\dot{\alpha}$ is the torsional angular velocity.

2.3.2. Force Element in Track Propulsion System. The track shoe is in contact with each wheel in two forms: the contact between the track pin and the gear teeth of the driving wheel at the meshing position; the contact between the track shoe plane and the road wheel, inducer, and towing wheel that is regarded as a smooth cylindrical surface. The above contact forms are shown in Figures 4(a) and $4(\mathrm{~b})$, respectively.

The contact force between the track shoe and each wheel is described by the Hertz collision theory, which is expressed as follows:

$$
F_{c}=-k_{w}\left(\partial-\partial_{0}\right)^{e}-c_{w} \dot{\partial},
$$

where $\partial$ is the generalized deformation caused by contact, $\partial_{0}$ is the critical deformation of the contact force, the degree of simulated deformation by $\partial-\partial_{0} ; \dot{\partial}$ is the deformation speed; $k_{w}$ is the contact stiffness coefficient of each wheel; $c_{w}$ is the maximum damping coefficient in the contact process; and $e$ is the nonlinear exponent.

In this paper, the hard pavement model was used for simulation calculation, and the contact model between the track and the hard pavement is shown in Figure 5.

When the track is in contact with the hard pavement, the interaction force between the two can be decomposed into normal force $P_{g}$ and tangential force $S_{g}$. Among them, the normal force $P_{g}^{g}$ is described by the contact collision theory, which is expressed as follows:

$$
P_{g}=k_{g} z_{g}+c_{g} \dot{z}_{g},
$$

where $k_{g}$ and $c_{g}$ are the contact stiffness coefficient and contact damping coefficient of the track-pavement, respectively; $z_{g}$ is the deformation variable of the track relative to the normal direction of the pavement; $\dot{z}_{g}$ is the deformation speed.

The tangential force $S_{g}$ is described by friction force and has a linear relationship with the normal force $P_{g}$, which is expressed as follows:

$$
S_{g}=-\mu_{g} P_{g}
$$

where $\mu_{g}$ is the friction coefficient. There is a relationship between the friction coefficient $\mu_{g}$ and the relative speed $v_{g}$ of the track-pavement measured by the test, which is expressed as follows:

$$
\mu_{g}=\mu_{g_{0}}\left[1-\exp \left(-a_{g} v_{g}\right)\right],
$$

where $\mu_{g_{0}}$ is the maximum static friction coefficient; $a_{g}$ is a positive constant.

2.4. System Dynamics Equation. A dynamic model was established based on the Cartesian coordinate system and using the Lagrangian equation of the first type. The generalized coordinate matrix of the model is

$$
\mathbf{q}_{n \times m}=\left[q_{1}, q_{2}, \ldots, q_{n}\right]^{T},
$$

where $n$ is the number of parts. For the complete track model, $n=231, m=6$.

The system constraint equation is

$$
\Phi(\mathbf{q}, t)=0 .
$$

The dynamic equations are

$$
\left[\begin{array}{cc}
\mathbf{M} & \boldsymbol{\Phi}_{q}^{T} \\
\boldsymbol{\Phi}_{q} & 0
\end{array}\right][\ddot{q} \lambda]=\left[\begin{array}{c}
\mathbf{F}_{e}+\mathbf{F}_{v} \\
\varphi
\end{array}\right]
$$

where $\Phi_{q}$ is the Jacobian matrix of the constraint equation, $\dot{q}$ is the generalized velocity matrix, $\ddot{q}$ is the generalized acceleration matrix of the model, $\mathbf{M}$ is the generalized mass matrix, $\lambda$ is the Lagrange multiplier, $\mathbf{F}_{e}$ is the generalized external force matrix, $\mathbf{F}_{v}$ is the inertial force matrix, and $\varphi$ is the right term of the equation.

On the basis of the above theoretical description and combined with the relevant design parameters of the action system of a certain type of high-speed tracked vehicle, a complete track model was established, as shown in Figure 6.

\section{Typical Pavement Simulation Modeling Method}

The method of establishing the digital pavement model is mainly to obtain the unevenness sequence of the pavement and establish the corresponding pavement input model by using the reconstruction method [17]. In this paper, a pavement simulation model was established by using the three-dimensional equivalent volume method [18]. Firstly, the pavement model was decomposed into several pavement nodes in three-dimensional space according to the typical pavement longitudinal profile shape and given pavement width. The coordinate $N_{i}\left(x_{i}, y_{i}, z_{i}\right)$ of the pavement nodes were mainly composed of the longitudinal position $x_{i}$, the width $y_{i}$, and the elevation $z_{i}$ of the pavement. Taking a simulated pavement containing 16 pavement nodes as an example, the node coordinates were arranged in a certain order and numbered to obtain the pavement node list, as shown in Table 4. 


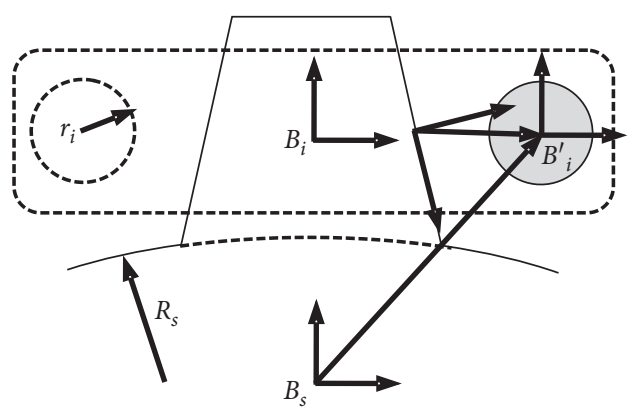

(a)

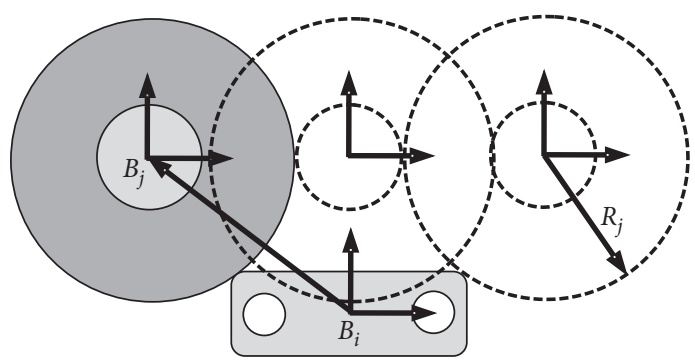

(b)

FIgURE 4: Two contact forms between track and wheels.

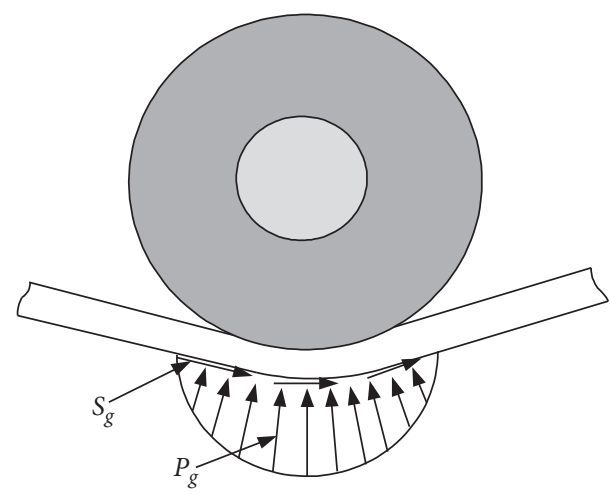

Figure 5: Contact model between track and hard pavement.

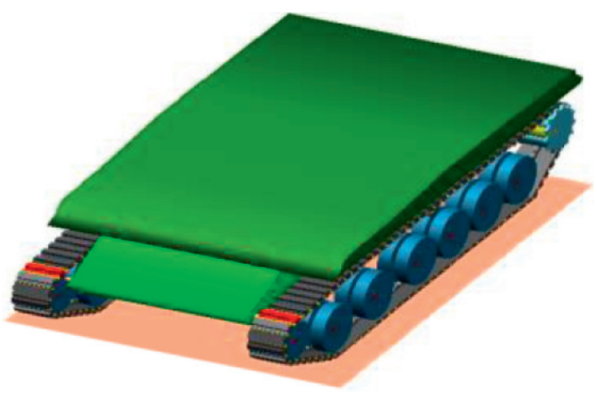

Figure 6: Dynamic model of high-speed tracked vehicle action system.

TABLE 4: List of simulated pavement nodes.

\begin{tabular}{lccccccc}
\hline $\begin{array}{l}\text { Serial } \\
\text { no. }\end{array}$ & $x(\mathrm{~m})$ & $y(\mathrm{~m})$ & $z(\mathrm{~m})$ & $\begin{array}{c}\text { Serial } \\
\text { no. }\end{array}$ & $x(\mathrm{~m})$ & $y(\mathrm{~m})$ & $z(\mathrm{~m})$ \\
\hline 1 & 0.0 & 5.0 & 0.0 & 9 & 10.15 & 5.0 & 0.5328 \\
2 & 0.0 & -5.0 & 0.0 & 10 & 10.15 & -5.0 & 0.6123 \\
3 & 10.0 & 5.0 & 0.0 & 11 & 10.20 & 5.0 & -0.7854 \\
4 & 10.0 & -5.0 & 0.0 & 12 & 10.20 & -5.0 & -0.1118 \\
5 & 10.05 & 5.0 & 0.7854 & 13 & 10.25 & 5.0 & 0.0 \\
6 & 10.05 & -5.0 & 0.1118 & 14 & 10.25 & -5.0 & 0.0 \\
7 & 10.10 & 5.0 & 0.0121 & 15 & 100 & 5.0 & 0.0 \\
8 & 10.10 & -5.0 & 0.0037 & 16 & 100 & -5.0 & 0.0 \\
\hline
\end{tabular}

According to the pavement node coordinates in the list, the three adjacent nodes were connected in sequence to generate 14 triangular pavement elements, as shown in
Table 5. In the process of simulation modeling, the static and dynamic friction coefficients of the pavement elements need to be defined.

A series of generated triangular pavement units were arranged in the space in serial number order to obtain the simulation model of the pavement, as shown in Figure 7.

Based on the above theoretical analysis, a list of pavement nodes and pavement units was compiled, and the pavement simulation models of various levels of uneven pavement, typical obstacle pavement, and test vehicle platform were established for dynamic model verification and simulation calculation, as shown in Figure 8.

\section{Simulation Calculation of Vibration Response of Uneven Pavement}

In order to establish a mathematical model with vibration response as the objective function and vehicle speed and pavement roughness as design variables, a large number of simulation results of high-speed tracked vehicles on different pavements and different speeds are needed.

In this paper, seven output responses of the system, such as the 3-way vibration acceleration at the driver's seat, the dynamic travel of the road wheel, and the 3-way vibration acceleration at the gunner's seat, were obtained via simulation calculation, which were converted into four evaluation indexes of vibration response, namely the RMS value of the total weighted acceleration of the driver's seat, the RMS value of the vertical acceleration of the driver's seat, the suspension dynamic travel, and the RMS value of the total weighted acceleration of the gunner's seat (replaced by evaluation index $y_{1}$, evaluation index $y_{2}$, evaluation index $y_{3}$, and evaluation index $y_{4}$ in the following sections), as shown in Table 6.

\section{Simulation Calculation of Vibration Response during Obstacle Crossing}

With reference to the calculation method of vehicle obstacle crossing in AMM-75 [19], two types of typical obstacles (trench and vertical wall) were selected to calculate the mathematical relationship between the maximum speed of vehicle obstacle crossing process and the size of obstacles, respectively. 
TABLE 5: List of simulated pavement units.

\begin{tabular}{|c|c|c|c|c|c|c|c|}
\hline Unit no. & Node no. & Node no. & Node no. & Unit no. & Node no. & Node no. & Node no. \\
\hline 1 & 1 & 2 & 3 & 8 & 8 & 10 & 9 \\
\hline 2 & 2 & 4 & 3 & 9 & 9 & 10 & 11 \\
\hline 3 & 3 & 4 & 5 & 10 & 10 & 12 & 11 \\
\hline 4 & 4 & 6 & 5 & 11 & 11 & 12 & 13 \\
\hline 5 & 5 & 6 & 7 & 12 & 12 & 14 & 13 \\
\hline 6 & 6 & 8 & 7 & 13 & 13 & 14 & 15 \\
\hline 7 & 7 & 8 & 9 & 14 & 14 & 16 & 15 \\
\hline
\end{tabular}

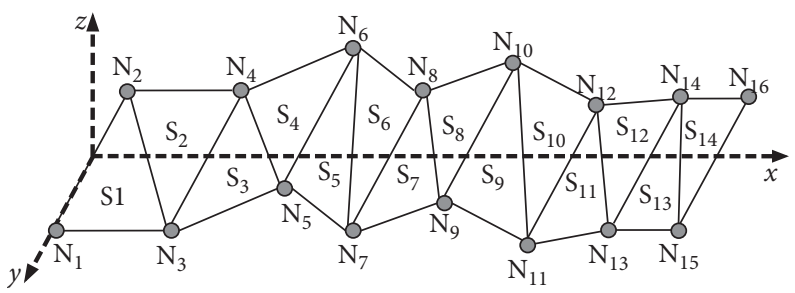

Figure 7: Schematic diagram of simulated pavement structure.

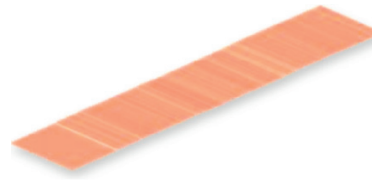

(a)

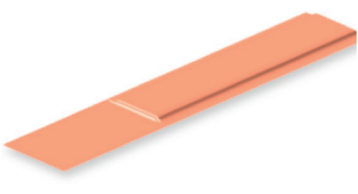

(b)

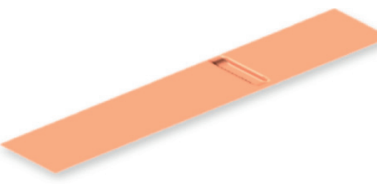

(c)

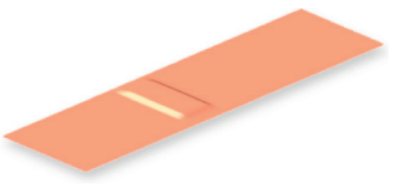

(d)

Figure 8: Typical pavement simulation model. (a) Uneven pavement. (b) Vertical wall. (c) Trench. (d) Automobile platform.

\subsection{Geometric Passability Analysis of High-Speed Tracked Vehicles}

5.1.1. Maximum Width of Surmountable Trench. A trench on a flat pavement can be simplified to a concave groove, as shown in Figure 9. It is assumed that the shape of the grooves does not change in the process of crossing obstacles, and the part that the vehicle passes is a hard pavement. The passability index of the tracked vehicle crossing the trench is the width $W$ of the trench in meters. The theoretical maximum trench width $W_{\max }$ can be deduced according to the design parameters such as the vehicle length, centroid position, driving wheel, and inducer wheel radius. The following two methods were used to deduce the maximum width of surmountable trench, and then the reliability of the results was verified by simulation calculation.

In Kuhner's study [20], an empirical formula for calculating the width of surmountable trench of tracked vehicles was proposed. When the vehicle meets that the centroid is in the half the length of $a+b+0.7\left(r_{f}+r_{r}\right)$, the maximum width of surmountable trench is

$$
W_{\max }=\frac{4}{9}\left[a+b+0.7\left(r_{f}+r_{r}\right)\right]
$$

where $a$ is the longitudinal distance from the driving wheel to the centroid of the vehicle; $b$ is the longitudinal distance from the idler wheel to the centroid of the vehicle; $r_{f}$ and $r_{r}$ are the radii of the driving wheel and the driving wheel, respectively.
The key dimensions of the high-speed tracked vehicles studied in this paper are shown in Table 7. The width of the trench calculated by formula (20) is $2.76 \mathrm{~m}$.

In Literature [21], a static overcoming method was proposed to study the maximum width of the vehicle over the trench. Whether a vehicle can cross a trench depends on the distance between the front and rear support points and the projection of the vehicle's centroid onto the plane. Taking the center of the inducer and driving wheel of the vehicle as the front and rear support points respectively, the maximum trench width should be equal to the minimum value of the longitudinal distance from the centroid of the vehicle to the front and rear support points, namely,

$$
W_{\max }=(a, b)_{\min } .
$$

According to Table 7 , the maximum width of surmountable trench of the vehicle was $2.68 \mathrm{~m}$ by using the static overriding method. In the actual driving process of the vehicle, the kinetic energy of the vehicle and the sliding of the track are usually enough to overcome a trench of greater width.

According to the calculation results, the trenches with a width of $2.7 \mathrm{~m}$ and a width of $2.75 \mathrm{~m}$ were selected for simulation calculation, and the vehicle speed was $6 \mathrm{~km} / \mathrm{h}$. The simulation calculation process of a vehicle crossing the trench is shown in Figure 10. It can be seen from Figure 10 that the vehicle can cross a $2.7 \mathrm{~m}$ wide longitudinal trench. However, in the process of crossing the $2.75 \mathrm{~m}$ wide trench, 
TABLE 6: Simulation results of vibration response evaluation index.

\begin{tabular}{|c|c|c|c|c|c|c|}
\hline \multirow[b]{2}{*}{ No. } & \multicolumn{2}{|l|}{ Model input } & \multicolumn{3}{|c|}{ System response output } & \multirow[b]{2}{*}{$\begin{array}{l}\text { RMS value of the total } \\
\text { weighted acceleration of } \\
\text { the gunner's seat }\left(\mathrm{m} / \mathrm{s}^{2}\right)\end{array}$} \\
\hline & $\begin{array}{c}\text { System response } \\
\text { output } \\
\left(\times 10^{3} \mathrm{~mm}^{2} / \mathrm{m}^{-1}\right)\end{array}$ & $\begin{array}{l}\text { Vehicle } \\
\text { speed } \\
(\mathrm{km} / \mathrm{h})\end{array}$ & $\begin{array}{l}\text { RMS value of the total } \\
\text { weighted acceleration of } \\
\text { the driver's seat }\left(\mathrm{m} / \mathrm{s}^{2}\right)\end{array}$ & $\begin{array}{l}\text { RMS value of the } \\
\text { vertical acceleration of } \\
\text { the driver's seat }\left(\mathrm{m} / \mathrm{s}^{2}\right)\end{array}$ & $\begin{array}{c}\text { Suspension } \\
\text { dynamic travel } \\
(\mathrm{m})\end{array}$ & \\
\hline 1 & 8.338 & 16.5 & 0.920 & 0.605 & 0.086 & 0.579 \\
\hline 2 & 12.726 & 38.4 & 1.684 & 1.099 & 0.156 & 1.009 \\
\hline 3 & 14.189 & 24.7 & 1.367 & 0.896 & 0.130 & 0.831 \\
\hline 4 & 1.755 & 46.6 & 0.697 & 0.453 & 0.066 & 0.406 \\
\hline 5 & 4.681 & 21.9 & 0.736 & 0.483 & 0.070 & 0.453 \\
\hline 6 & 5.412 & 43.9 & 1.152 & 0.751 & 0.107 & 0.684 \\
\hline 7 & 14.921 & 49.4 & 2.130 & 1.387 & 0.192 & 1.284 \\
\hline 8 & 9.801 & 2.7 & 0.708 & 0.470 & 0.062 & 0.498 \\
\hline 9 & 10.532 & 27.4 & 1.281 & 0.838 & 0.121 & 0.774 \\
\hline 10 & 7.606 & 54.9 & 1.618 & 1.052 & 0.144 & 0.977 \\
\hline 11 & 16.384 & 35.7 & 1.761 & 1.150 & 0.165 & 1.058 \\
\hline 12 & 3.218 & 32.9 & 0.729 & 0.476 & 0.070 & 0.431 \\
\hline 13 & 15.652 & 11.0 & 0.986 & 0.652 & 0.095 & 0.634 \\
\hline 14 & 9.069 & 41.1 & 1.481 & 0.966 & 0.137 & 0.885 \\
\hline 15 & 11.264 & 52.1 & 1.937 & 1.261 & 0.173 & 1.168 \\
\hline 16 & 6.144 & 8.2 & 0.644 & 0.426 & 0.056 & 0.438 \\
\hline 17 & 11.995 & 13.7 & 1.016 & 0.669 & 0.096 & 0.645 \\
\hline 18 & 1.024 & 19.2 & 0.324 & 0.213 & 0.030 & 0.208 \\
\hline 19 & 2.486 & 5.5 & 0.342 & 0.227 & 0.025 & 0.265 \\
\hline 20 & 6.875 & 30.2 & 1.068 & 0.698 & 0.101 & 0.640 \\
\hline 21 & 6.509 & 1.4 & 0.558 & 0.370 & 0.045 & 0.414 \\
\hline 22 & 15.286 & 4.1 & 0.788 & 0.525 & 0.075 & 0.540 \\
\hline 23 & 12.361 & 6.9 & 0.855 & 0.566 & 0.079 & 0.570 \\
\hline 24 & 10.167 & 9.6 & 0.864 & 0.571 & 0.080 & 0.567 \\
\hline 25 & 13.458 & 12.3 & 1.012 & 0.668 & 0.097 & 0.646 \\
\hline 26 & 1.389 & 15.1 & 0.328 & 0.217 & 0.029 & 0.223 \\
\hline 27 & 14.555 & 17.8 & 1.180 & 0.776 & 0.113 & 0.732 \\
\hline 28 & 3.949 & 20.6 & 0.648 & 0.425 & 0.061 & 0.402 \\
\hline 29 & 2.852 & 23.3 & 0.570 & 0.374 & 0.054 & 0.349 \\
\hline 30 & 7.240 & 26.1 & 1.024 & 0.670 & 0.097 & 0.619 \\
\hline 31 & 16.018 & 28.8 & 1.534 & 1.004 & 0.146 & 0.925 \\
\hline 32 & 9.435 & 31.5 & 1.301 & 0.850 & 0.123 & 0.781 \\
\hline 33 & 8.704 & 34.3 & 1.304 & 0.851 & 0.122 & 0.780 \\
\hline 34 & 2.121 & 37.0 & 0.639 & 0.417 & 0.062 & 0.372 \\
\hline 35 & 10.898 & 39.8 & 1.598 & 1.043 & 0.148 & 0.955 \\
\hline 36 & 5.047 & 42.5 & 1.086 & 0.708 & 0.101 & 0.643 \\
\hline 37 & 3.584 & 45.3 & 0.940 & 0.612 & 0.088 & 0.555 \\
\hline 38 & 5.778 & 48.0 & 1.266 & 0.824 & 0.116 & 0.754 \\
\hline 39 & 11.630 & 50.7 & 1.934 & 1.258 & 0.174 & 1.164 \\
\hline 40 & 7.972 & 53.5 & 1.632 & 1.062 & 0.146 & 0.984 \\
\hline
\end{tabular}

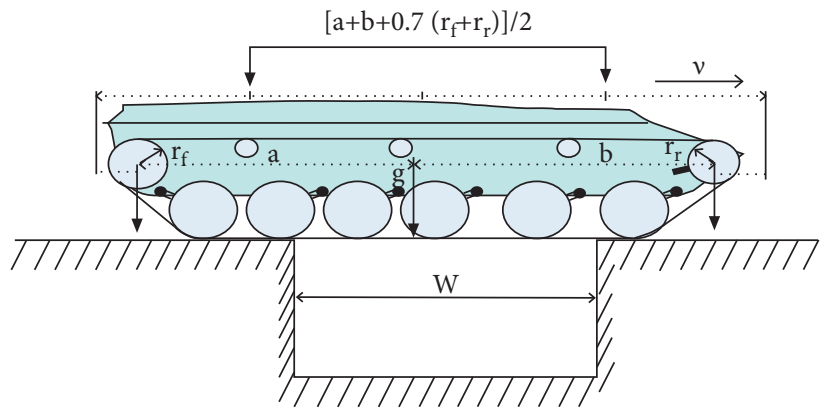

FIgURE 9: Key parameters of vehicle crossing trench.

TABLE 7: Key parameters of vehicle crossing trench.

\begin{tabular}{lcccc}
\hline Parameter symbol & $r_{f}(\mathrm{~m})$ & $r_{r}(\mathrm{~m})$ & $a(\mathrm{~m})$ & $b(\mathrm{~m})$ \\
\hline Value & 0.26 & 0.31 & 2.68 & 3.12 \\
\hline
\end{tabular}


the front end of the vehicle fell, and the simulation failed after the collision with the cliff wall. After simulation verification, the maximum width of surmountable trench of the vehicle was $2.7 \mathrm{~m}$. Figures 11 and 12 respectively show the vertical acceleration of the centroid of the vehicle and the vertical load received by each road wheel during the simulation process of the vehicle crossing the $2.7 \mathrm{~m}$ trench.

It can be seen that the acceleration at the centroid of the vehicle changes very drastically, with a peak acceleration of $20 \mathrm{~m} / \mathrm{s}^{2}$, which is close to the limit value of $2.5 \mathrm{~g}$ for the human body to be subjected to shock response. In the process of crossing obstacles, both the human body and the vehicle's mobile devices bear the huge shock caused by the obstacle to the vehicle, and the vibration and shock response of the vehicle are closely related to the driving speed. Therefore, in the process of overcoming the trench, the vehicle should slow down as much as possible to avoid the discomfort of occupants and the damage of vehicle parts caused by excessive vibration response.

5.1.2. Maximum Height over a Vertical Wall. The process of a high-speed tracked vehicle crossing a vertical wall can be divided into three stages $[21,22]$ : the first stage is the process starting from the front wheel of the vehicle, i.e., the inducer wheel, which reaches the edge of the vertical wall ended with the front wheel axle rising to the seamed edge of the vertical wall; the second stage refers to the process from the end of the previous stage till the line of gravity of the vehicle coinciding with the seamed edge of the vertical wall; and the third stage is from the end of the previous stage till all vehicles fall on the top plane of the vertical wall.

The passability indicator of the vehicle over the vertical wall is the vertical wall of height $\mathrm{H}$, and the maximum height is determined by the first and second stages. In the first stage, the maximum height that the vehicle can pass through the vertical wall depends on the amount of slippage of the track and the soil characteristics of the vertical wall itself, and the calculation is rather complicated. Based on the height of the inducer axis, the height of the vertical wall normally can be directly predicted. For the vehicle model studied in this paper, the axis of the inducer is $0.74 \mathrm{~m}$ high from the ground, and the vertical wall height that can be passed via the track sliding is about $0.9 \mathrm{~m}$.

In the second stage, the vehicle was in the final position, as shown in Figure 13. At this point, the line of gravity of the vehicle coincided with the seamed vertical edge of the vertical wall, and the calculation formula to obtain the height of the vertical wall via the geometric relationship is as follows:

$$
H=L_{s} \sin \alpha+h_{s} \cos \alpha+\frac{h_{r}}{\cos \alpha}+r-\frac{h_{g}}{\cos \alpha},
$$

where $\alpha$ is the trim angle of the vehicle; $h_{s}$ is the height difference between the centroid of the vehicle and the axis of the driving wheel; $L_{s}$ is the longitudinal distance from the centroid to the axis of the driving wheel when the vehicle is on a flat pavement; $h_{g}$ is the height of the centroid from the ground when the vehicle is horizontal; $h_{r}$ is the dynamic travel of the road wheel; $r_{r}$ is the radius of the driving wheel.

For the selected vehicle type, the relevant parameters used for calculation are shown in Table 8. Taking the trim angle as $30^{\circ}$ and putting it into formula (22), the maximum height of the vertical wall that can pass through in the second stage was $1.09 \mathrm{~m}$.

According to theoretical calculations, the maximum height that the vehicle can pass through the vertical wall was $0.9 \mathrm{~m}$. The vertical walls of $0.9 \mathrm{~m}$ and $1.0 \mathrm{~m}$ height were respectively used for simulation calculation, and the vehicle speed was still $6 \mathrm{~km} / \mathrm{h}$. Through simulation calculation, the vehicle can pass through a vertical wall of $0.9 \mathrm{~m}$ successfully but cannot pass a vertical wall of $1.0 \mathrm{~m}$, as shown in Figure 14.

The postprocessing results of the simulation calculation are shown in Figures 15 and 16. It shows that as the simulation time is about $8.3 \mathrm{~s}$, the vehicle received a greater vertical shock from the complete collision caused by the front end of the vehicle contacting the vertical wall. At this time, the vertical acceleration of the vehicle's centroid was $19.5 \mathrm{~m} / \mathrm{s}^{2}$, and the vertical load of the road wheels changed drastically, with a peak value of $0.75-1.5 \times 10^{5} \mathrm{~N}$. The acceleration of the centroid of the vehicle and the peak value of the vertical load of the road wheels were related to the driving speed of the vehicle. The higher the speed of a vehicle crossing the vertical wall, the stronger the shock vibration generated by the collision, and the greater the shock was, the greater the shock on the comfort of the occupants and the stability of the vehicle was.

5.2. Simulation Calculation of Vibration Response in the Process of Crossing Obstacle. In order to calculate and evaluate the off-road mobility of tracked vehicles through the pavement with obstacles, trenches and vertical walls were selected as typical obstacles, vehicle speed and obstacle size were used as design variables, and a large number of simulation calculations were carried out based on the experimental design based on the established dynamic model of the tracked vehicle movement system. Supposing that the distribution ranges of the width of trench and the height of vertical wall were $(2.0 \mathrm{~m}, 2.7 \mathrm{~m})$ and $(0.4 \mathrm{~m}, 0.9 \mathrm{~m})$, respectively, and the value ranges of vehicle speed were $(7.2 \mathrm{~km} / \mathrm{h}, \quad 57.6 \mathrm{~km} / \mathrm{h})$ and $(3.6 \mathrm{~km} / \mathrm{h}, \quad 28.8 \mathrm{~km} / \mathrm{h})$, respectively.

In order to fully reflect the system response in the designed space, a full factorial experimental design method was adopted, and 8-level trench widths and 8-level vehicle speeds at equal intervals were selected to simulate the process of 64 groups of vehicles crossing the trench; at the same time, 6 levels of vertical wall heights and 8 levels of vehicle speeds at equal intervals were selected to perform simulation calculations for 48 groups of vehicles passing through the vertical wall. And the maximum peak value of the vertical acceleration at the driver's seat was obtained through simulation calculation. The simulation results are shown in Tables 9 and 10, respectively. 


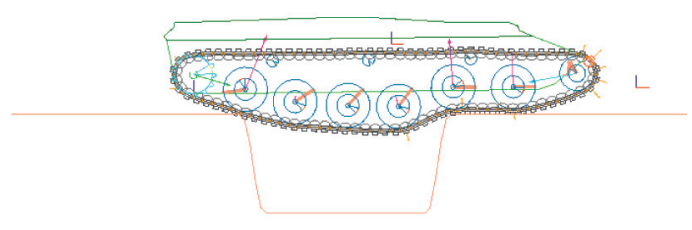

(a)

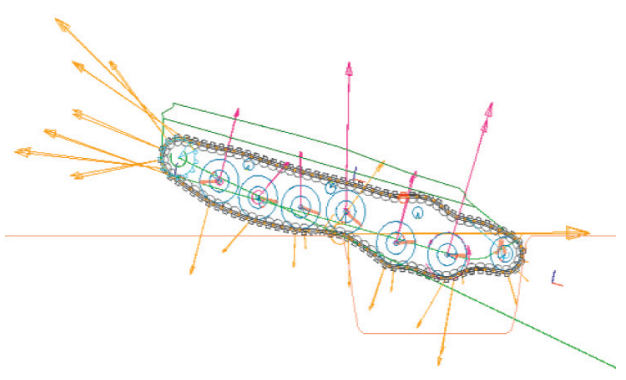

(b)

FIGURE 10: Simulation process of vehicle crossing trench. (a) $2.7 \mathrm{~m}$ trench. (b) $2.75 \mathrm{~m}$ trench.

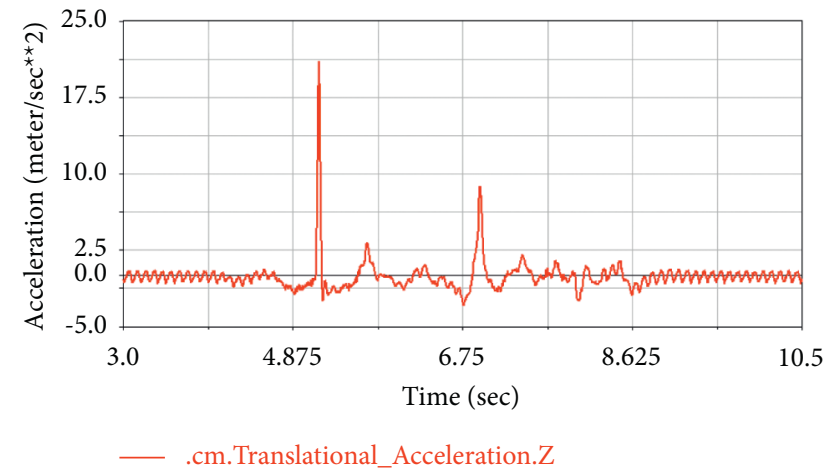

FIGURE 11: Vertical acceleration of the centroid in the process of crossing the trench.

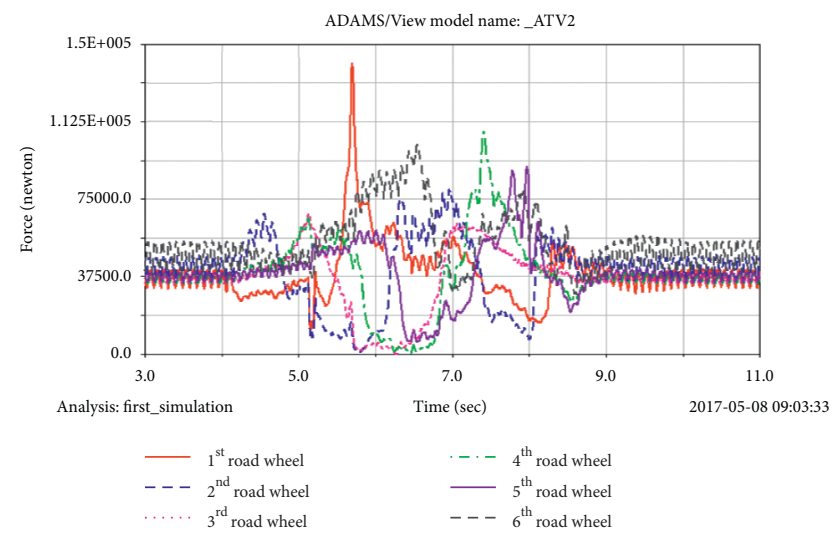

Figure 12: Vertical load of each road wheel in the process of crossing the trench.

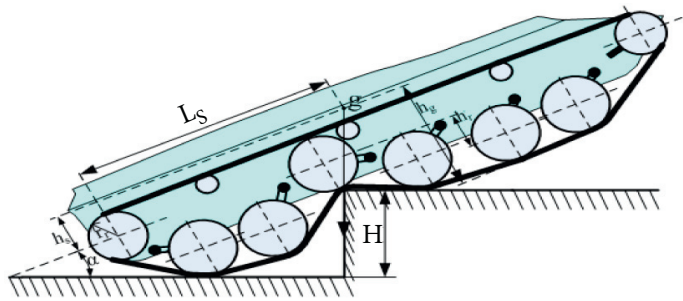

FIGURE 13: Key parameters of a vehicle crossing a vertical wall.
TABLE 8: Key parameters of a vehicle crossing a vertical wall.

\begin{tabular}{lccccc}
\hline Parameter symbol & $h_{s}(\mathrm{~m})$ & $L_{s}(\mathrm{~m})$ & $h_{g}(\mathrm{~m})$ & $h_{r}(\mathrm{~m})$ & $r_{r}(\mathrm{~m})$ \\
\hline Parameter value & 0.23 & 2.68 & 1.01 & 0.35 & 0.31 \\
\hline
\end{tabular}

\section{Experiments and Model Verification}

In order to verify the credibility of the model, experiments were made on an uneven road and a vehicle obstacle platform, as shown in Figure 17 according to the Armored Vehicle Experment Rules-Vibration Field Test (GJB59.1588 , in Chinese). The vibration signals at the position under the driver's seat were collected.

6.1. Tests on Uneven Road. The vehicle ran at the $3^{\text {rd }}$ gear and $4^{\text {th }}$ gear when testing. The measured acceleration at the position just under the driver's seat is shown in Figures 18 and 19. The PSD spectrums are shown in Figures 20 and 21. The RMS values of the measured and simulated acceleration are shown in Table 11. The frequencies of the test vibration compared with the simulation values are shown in Table 12.

6.2. Tests on Obstacle Platform. The vehicle ran at the $1^{\text {st }}$ gear when testing. The vertical acceleration measured at the vehicle boby just above the first road wheel is shown in Figure 22. PSD of the vibration signal is shown in Figure 23. The RMS values of the test and simulation data are shown in Table 13.

Figures 18 to 23 show that the change trend of simulation and test waves is basically the same. The key values of simulation in low frequency band are not much different from the test values. The test data have a wider frequency band because of speed changes or disturbing noise, but the peak frequency of simulation data in higher frequency band is similar to the test results. The experiments show that the built model can better reflect the vibration characteristics of the vehicle.

\section{Vibration Response Approximation Model and Accuracy Test}

Since the relationship between the design variables and the objective function obtained by experimental design and 


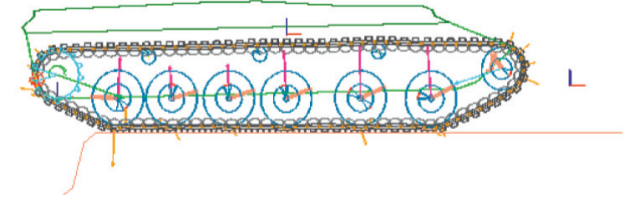

(a)

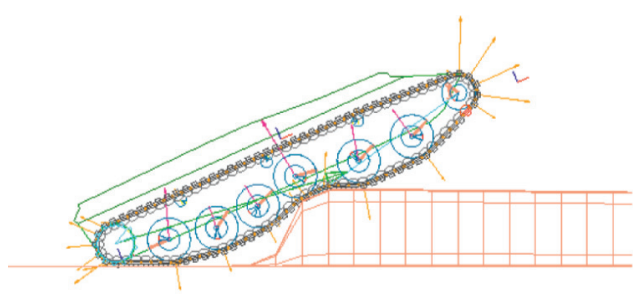

(b)

FIgURE 14: Simulation process of a vehicle crossing a vertical wall. (a) $0.9 \mathrm{~m}$ vertical wall. (b) $1.0 \mathrm{~m}$ vertical wall.

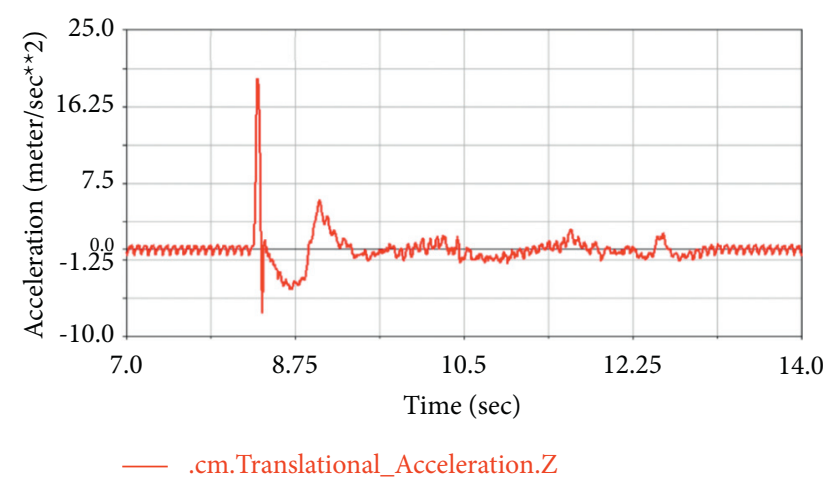

Figure 15: Vertical acceleration of centroid in the process of crossing a vertical wall.

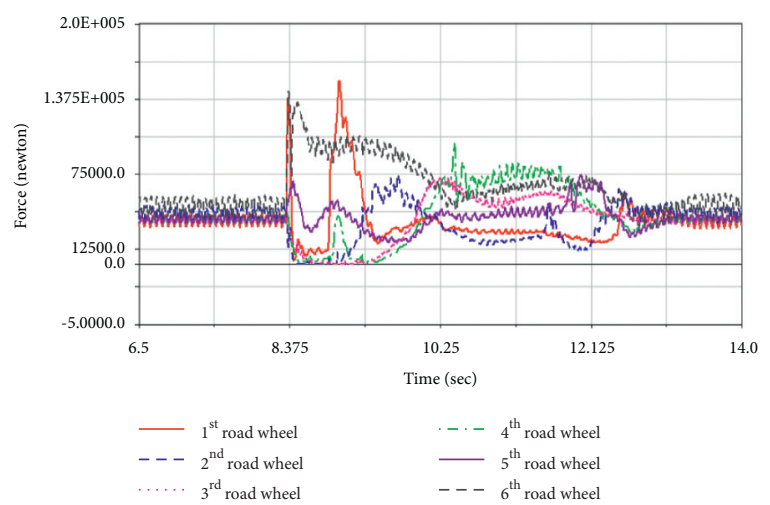

Figure 16: Vertical load of each load wheel in the process of crossing a vertical wall.

simulation calculation is an unknown implicit function, the establishment of a high-quality approximation model to replace the original complex multibody model can effectively improve efficiency and reduce the actual computation time by orders of magnitude and meanwhile also remove the influence of numerical noise.

Approximation model $[23,24]$ is the use of approximation technology to fit or interpolate discrete data to obtain a simple and intuitive mathematical model to describe the relationship between system design variables and response characteristics. And a calculation result similar to that of a complex model usually can be obtained through predicting the response of unknown points with limited data samples.
Commonly used basic approximation model fitting methods include the polynomial response surface method (PRSM) [25, 26], Kriging method [27], and radial basis function (RBF) neural network $[28,29]$. The fitting accuracy of the approximation models obtained by different methods varies greatly. Therefore, this paper used these three fitting methods to establish the approximation models between the design variables and the objective function, and calculated the approximate error between predicted value of the fitted model and the response values of actual simulation model to compare and analyze the pros and cons of each model, and the approximation model with the highest accuracy was selected.

\subsection{Approximate Model of Uneven Pavement Response}

7.1.1. Approximate Model of Polynomial Response Surface. According to 40 groups of simulation calculation results, the second-order polynomial response surface model between the two design variables of vehicle speed and pavement unevenness and the four vibration response evaluation indicators was fitted according to the above method, as shown in Figure 24.

In Figure 24, the horizontal axis refers to the pavement roughness coefficient and the vehicle speed, and the vertical axis refers to the value of a vibration response evaluation index calculated by the second-order polynomial response surface model. It is shown that the increase of the pavement roughness coefficient indicates worse pavement conditions, and as the pavement conditions become worse and the vehicle speed increases, the system's output response evaluation indicators increase monotonously, which can reflect the vibration characteristics of the vehicle on uneven pavements.

7.1.2. Kriging Approximation Model. All the selected 40 sample points was adopted to construct the Kriging approximation model between the two design variables of the vehicle speed and pavement unevenness and the four vibration response evaluation indicators according to the above method, as shown in Figure 25.

In Figure 25, the horizontal axis represents the magnitude of the pavement roughness coefficient and the vehicle speed, respectively, while the vertical axis represents the magnitude of the vibration response evaluation index calculated by the Kriging approximate model. It can be seen that the increase of the pavement roughness coefficient 
TABLE 9: Simulation results of the maximum peak value of the vertical acceleration at the driver's seat when vehicle crossing trench $\left(\mathrm{m} / \mathrm{s}^{2}\right)$.

\begin{tabular}{|c|c|c|c|c|c|c|c|c|}
\hline \multicolumn{9}{|c|}{ Speed $(\mathrm{km} / \mathrm{h})$} \\
\hline Width (m) & 7.2 & 14.4 & 21.6 & 28.8 & 36 & 43.2 & 50.4 & 57.6 \\
\hline 2.0 & 11.651 & 11.871 & 13.734 & 14.265 & 16.103 & 17.798 & 18.368 & 20.447 \\
\hline 2.1 & 12.727 & 16.675 & 18.312 & 17.568 & 17.243 & 19.367 & 21.516 & 23.021 \\
\hline 2.2 & 14.469 & 21.422 & 20.015 & 18.312 & 19.223 & 21.159 & 24.117 & 25.216 \\
\hline 2.3 & 17.287 & 25.512 & 22.976 & 20.247 & 21.107 & 22.516 & 25.805 & 26.412 \\
\hline 2.4 & 34.589 & 32.074 & 24.816 & 20.719 & 22.216 & 24.854 & 26.571 & 27.382 \\
\hline 2.5 & 43.175 & 38.451 & 26.351 & 22.123 & 24.107 & 25.541 & 28.146 & 28.017 \\
\hline 2.6 & 53.852 & 49.051 & 32.801 & 22.154 & 25.108 & 26.571 & 29.237 & 29.306 \\
\hline 2.7 & 64.793 & 52.316 & 34.952 & 23.773 & 26.121 & 27.671 & 29.619 & 29.945 \\
\hline
\end{tabular}

TABLE 10: Simulation results of the maximum peak value of the vertical acceleration at the driver's seat when vehicle crossing a vertical wall $\left(\mathrm{m} / \mathrm{s}^{2}\right)$.

\begin{tabular}{|c|c|c|c|c|c|c|c|c|}
\hline \multicolumn{9}{|c|}{ Speed $(\mathrm{km} / \mathrm{h})$} \\
\hline Width (m) & 3.6 & 7.2 & 10.8 & 14.4 & 18 & 21.6 & 25.2 & 28.8 \\
\hline 0.4 & 4.532 & 8.121 & 9.863 & 12.356 & 14.734 & 23.417 & 25.723 & 28.291 \\
\hline 0.5 & 5.711 & 14.957 & 21.336 & 34.339 & 38.626 & 40.152 & 47.393 & 54.174 \\
\hline 0.6 & 7.169 & 16.843 & 23.537 & 37.185 & 46.316 & 50.367 & 54.849 & 61.814 \\
\hline 0.7 & 8.509 & 19.127 & 28.854 & 40.931 & 51.743 & 58.171 & 65.392 & 73.295 \\
\hline 0.8 & 10.266 & 21.079 & 30.259 & 43.127 & 57.119 & 66.034 & 75.905 & 82.162 \\
\hline 0.9 & 15.001 & 26.726 & 31.812 & 47.634 & 67.313 & 73.673 & 80.376 & 85.247 \\
\hline
\end{tabular}

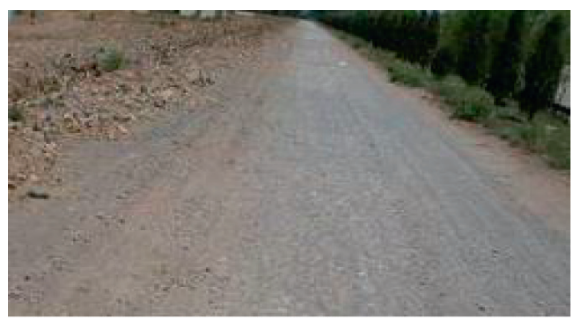

(a)

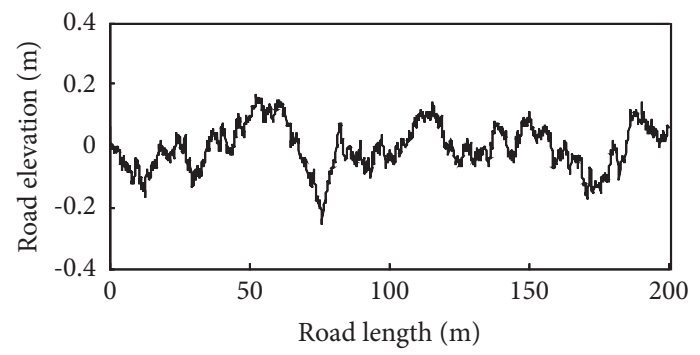

(c)

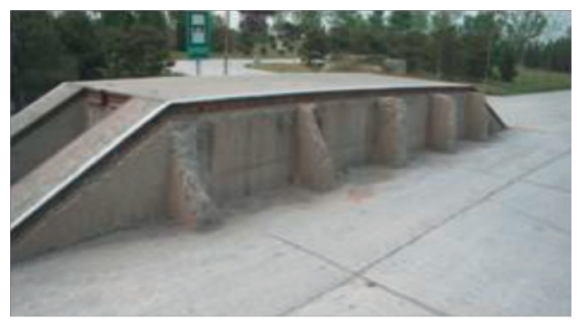

(b)

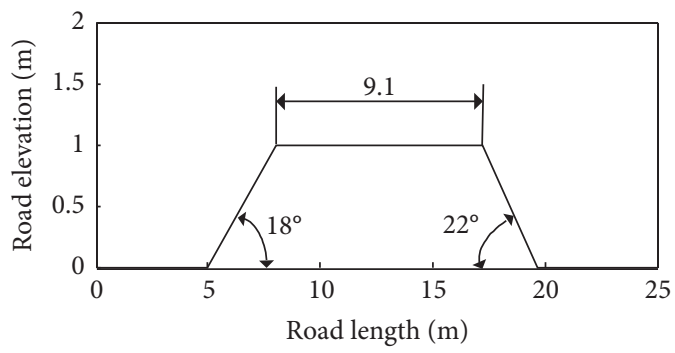

(d)

Figure 17: Typical experiment road. (a) Random uneven road. (b) Vehicle obstacle platform. (c) Uneven road curve. (d) Obstacle platform structure.

represents that the driving conditions become worse. As the pavement condition gets worse and the speed accelerates, the evaluation indexes of the output response of the system all increase monotonically; when the pavement and vehicle speed approach the upper limit of the sample space, the change of the output response tends to be gentle.

7.1.3. Approximate Model of RBF Neural Network. All the 40 sample points selected were used to train the RBF neural network, and the approximate model between the two design variables, speed and pavement roughness, and the four vibration response evaluation indexes was obtained, as shown in Figure 26.

In Figure 26, the horizontal axis represents the magnitude of the pavement roughness coefficient and the vehicle speed, while the vertical axis represents the magnitude of the vibration response evaluation index calculated by the RBF neural network model. The variation trend of the curved surface drawn is basically the same as that of the second-order response surface model, 


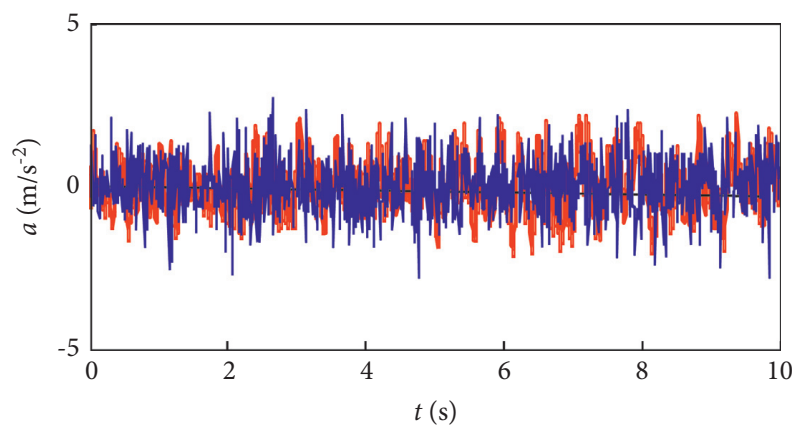

- Simulated

- - - Measured

FIGURE 18: Vibration in the $3^{\text {rd }}$ gear condition.

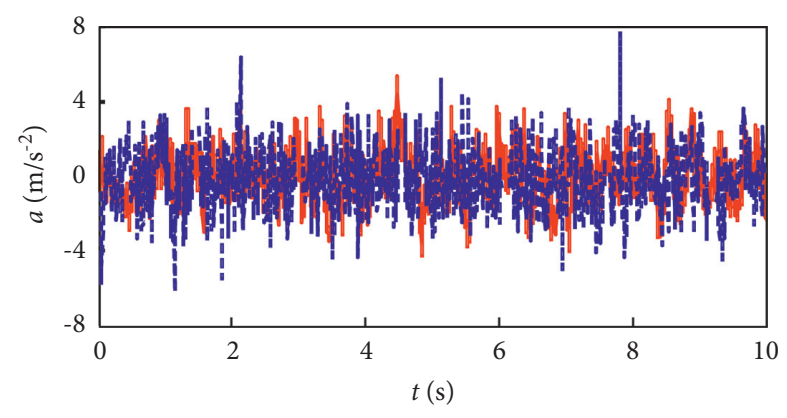

- Simulated

- - - Measured

FIgURE 19: Vibration in the $4^{\text {th }}$ gear condition.

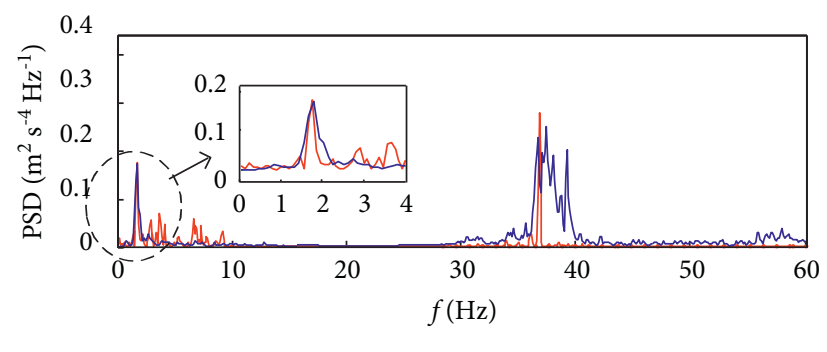

_ simulated

- measured

FIgURE 20: PSD of acceleration in the 3rd gear condition.

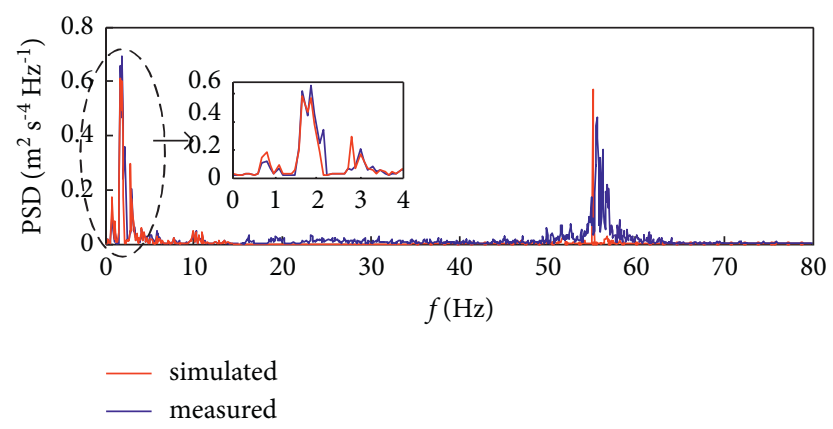

FIgURE 21: PSD of acceleration in the 4th gear condition.

TABLE 11: RMS values of the test compared with the simulation values.

\begin{tabular}{lccc}
\hline Gear & Vehicle speed & Measured RMS & Simulated RMS \\
\hline $3^{\text {rd }}$ gear & $22 \mathrm{~km} / \mathrm{h}$ & $0.811 \mathrm{~m} / \mathrm{s}^{2}$ & $0.767 \mathrm{~m} / \mathrm{s}^{2}$ \\
$4^{\text {th }}$ gear & $31 \mathrm{~km} / \mathrm{h}$ & $1.126 \mathrm{~m} / \mathrm{s}^{2}$ & $1.088 \mathrm{~m} / \mathrm{s}^{2}$ \\
\hline
\end{tabular}


TABLE 12: Frequencies of the test vibration compared with the simulation values.

\begin{tabular}{lcccc}
\hline Gear & Vehicle speed & Order & Measured frequency & Simulated frequency \\
\hline \multirow{2}{*}{$3^{\text {rd }}$ gear } & \multirow{2}{*}{$22 \mathrm{~km} / \mathrm{h}$} & 1 & - & - \\
& & 2 & $1.787 \mathrm{~Hz}$ & $1.749 \mathrm{~Hz}$ \\
\hline \multirow{2}{*}{$3^{\text {rd }}$ gear } & $31 \mathrm{~km} / \mathrm{h}$ & 3 & $37.43 \mathrm{~Hz}$ & $36.82 \mathrm{~Hz}$ \\
& & 2 & $0.786 \mathrm{~Hz}$ & $0.830 \mathrm{~Hz}$ \\
& & 3 & $1.648 \mathrm{~Hz}$ & $1.662 \mathrm{~Hz}$ \\
\hline
\end{tabular}

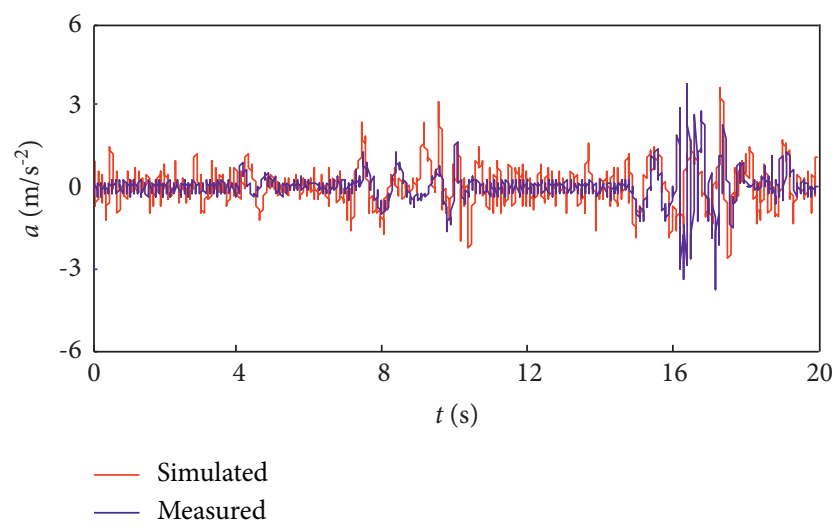

FIgURE 22: Vibration signal when passing through obstacle platform.

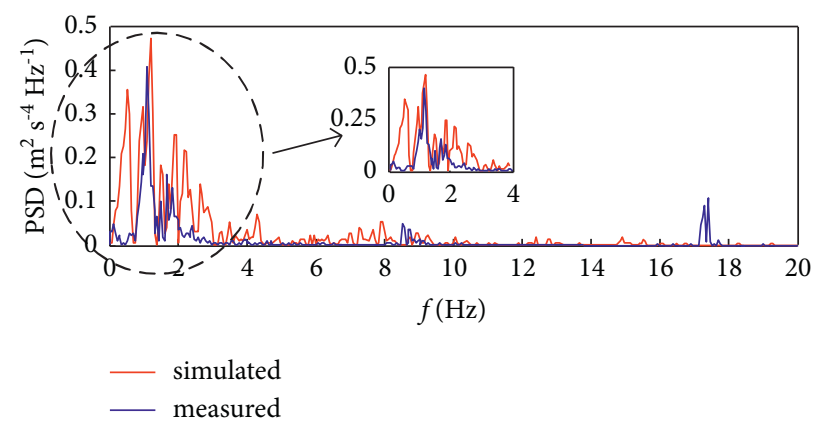

FIGURE 23: PSD of the vibration signal when passing though obstacle platform.

TABLE 13: The vertical acceleration measured at the position above the first road wheel compared with simulated values.

\begin{tabular}{lccc}
\hline Parameters & Measured values & Simulation values & Error \\
\hline Peak value & $3.704 \mathrm{~m} / \mathrm{s}^{2}$ & $3.892 \mathrm{~m} / \mathrm{s}^{2}$ & $5.0 \%$ \\
RMS & $0.639 \mathrm{~m} / \mathrm{s}^{2}$ & $0.625 \mathrm{~m} / \mathrm{s}^{2}$ & $2.3 \%$ \\
Natural frequency & $1.56 \mathrm{~Hz}$ & $1.61 \mathrm{~Hz}$ & $3.2 \%$ \\
\hline
\end{tabular}

which can better reflect the vibration characteristics of the vehicle.

7.2. Accuracy Test of Approximate Model Fitting for Uneven Pavement Response. In order to compare the pros and cons of the above three methods, the accuracy of these three approximate models needs to be tested so as to select the optimal model that can reflect the relationship between the design variables and the response value to the greatest extent. Fifteen sample points were randomly selected, the actual and predicted values of the evaluation indexes corresponding to the 15 sample points were calculated by using the dynamic model and the approximate model, respectively, and the degree of similarity between the approximate model and the original model was quantitatively analyzed by using $R^{2}$ and RMSE.

(1) The $R^{2}$ test method was used to evaluate the fitting accuracy of the three approximate models, as shown in Table 14. Among them, the $R^{2}$ of both the polynomial response surface model and the RBF neural network model reached more than 9.5, while that of the Kriging model was only about 9, indicating that the fitting accuracy of the Kriging model was far lower than the other two models.

(2) RMSE was used to quantitatively evaluate the fitting accuracy of the three approximate models, as shown 

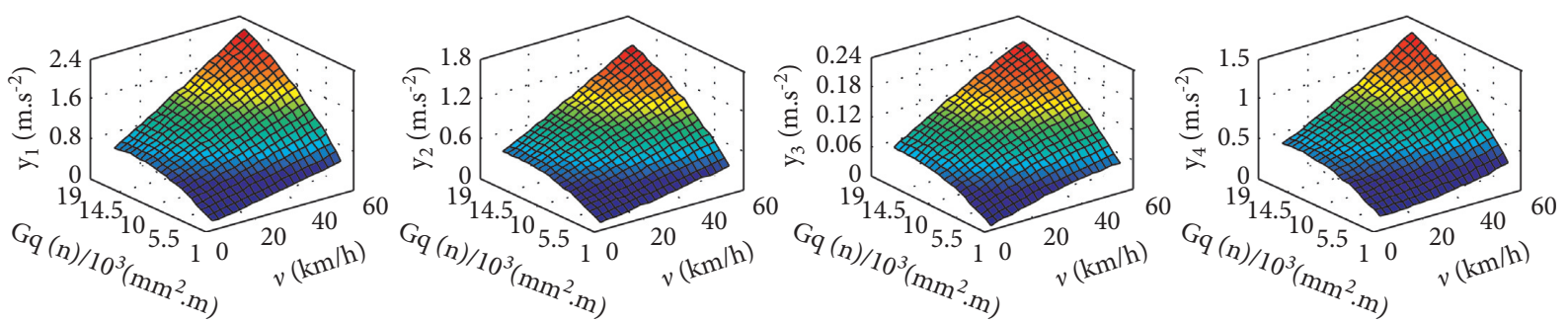

FIGURE 24: Model fitting of second-order polynomial response surface.
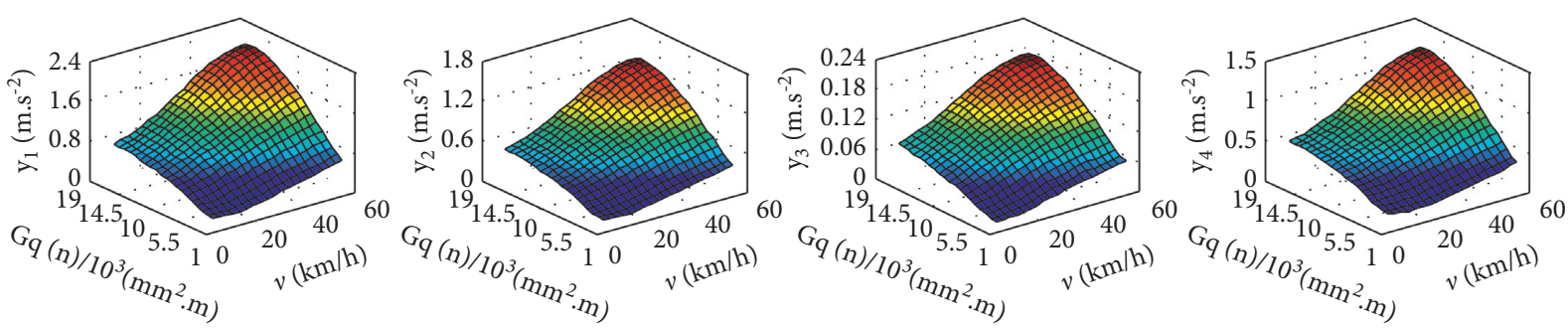

FIGURE 25: Kriging approximate model fitting.
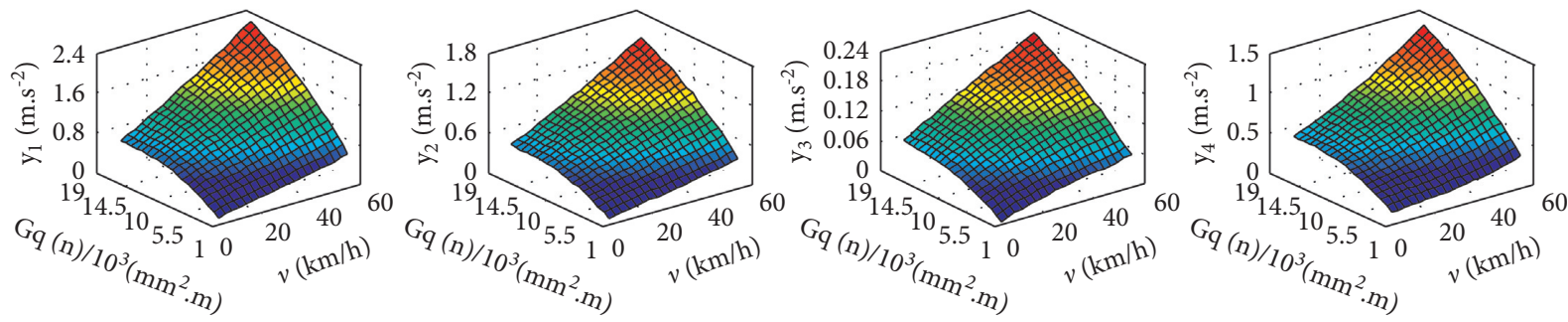

FIGURE 26: RBF neural network model fitting.

TABLe 14: $R^{2}$ of approximate model.

\begin{tabular}{lccc}
\hline Vibration response evaluation indices & & $R^{2}$ & \\
& Polynomial response surface & Kriging model & RBF neural network \\
\hline Evaluation index $y 1$ & 0.986 & 0.913 & 0.986 \\
Evaluation index $y 2$ & 0.967 & 0.891 & 0.976 \\
Evaluation index $y 3$ & 0.955 & 0.863 & 0.946 \\
Evaluation index $y 4$ & 0.980 & 0.910 & 0.979 \\
\hline
\end{tabular}

in Table 15. Among them, the RMSE of the Kriging model was the largest, while that of the RBF neural network approximation model was the smallest, providing the optimal fitting accuracy.

Based on the results of the $R^{2}$ test and the RMSE test, the approximate model of the RBF neural network can be used to fit the mathematical relationship between pavement roughness, speed, and vibration response.

\subsection{Approximate Model and Test of Obstacle Crossing Process System}

7.3.1. Approximate Model of the Process of Vehicle Crossing Trench. According to the simulation results of the vehicle crossing the trench, three fitting methods are as follows: the polynomial response surface, the Kriging approximation model, and the RBF neural network were used to construct the relationship between the vibration response evaluation index (the shock vibration peak value, replaced by evaluation index $y 5$ in the following sections) and the two variables of the vehicle speed and trench width. The approximate model obtained is shown in Figure 27.

The approximate model fitting results show that when the vehicle speed is low, the vibration response varies greatly with the change of the trench width. When a vehicle passes a trench with a width greater than $2.3 \mathrm{~m}$, the vibration response increases first and then decreases with the increase of vehicle speed; when a vehicle passes a trench with a width less than $2.3 \mathrm{~m}$, the vibration response increases approximately monotonously with the increase of the vehicle speed.

Ten groups of test points were randomly selected from the sample space, and the multiple correlation coefficient and relative RMSE were used to test the fitting accuracy of 
TABLE 15: RMSE of approximate model.

\begin{tabular}{lccc}
\hline Vibration response evaluation indices & & RMSE & \\
& Polynomial response surface & Kriging model & RBF neural network \\
\hline Evaluation index $y 1$ & 0.0258 & 0.0732 & 0.0212 \\
Evaluation index $y 2$ & 0.0356 & 0.0737 & 0.0309 \\
Evaluation index $y 3$ & 0.0417 & 0.0805 & 0.0323 \\
Evaluation index $y 4$ & 0.0235 & 0.0666 & 0.0171 \\
\hline
\end{tabular}

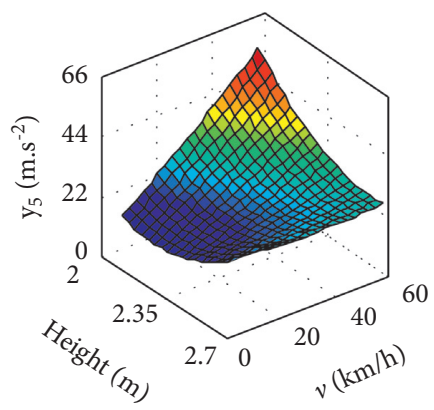

(a)

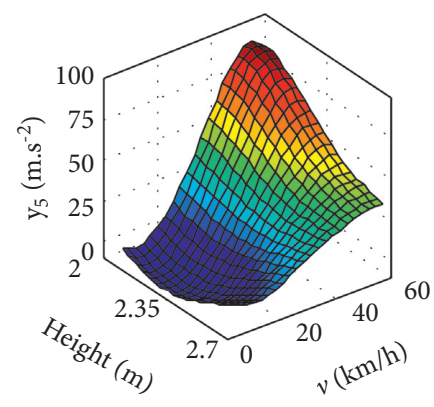

(b)

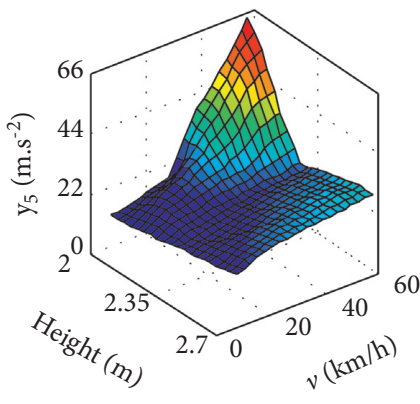

(c)

Figure 27: Approximate model of the process of vehicle crossing trench. (a) Polynomial response surface. (b) Kriging model. (c) RBF neural network.

TABle 16: Accuracy test of approximate model of vehicle crossing trench.

\begin{tabular}{lccc}
\hline Test coefficient & Polynomial response surface & Kriging model & RBF neural network \\
\hline$R^{2}$ & 0.906 & 0.862 & 0.924 \\
RMSE & 0.0115 & 0.0631 & 0.0174 \\
\hline
\end{tabular}

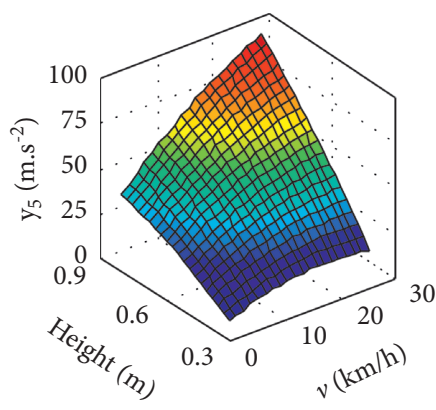

(a)

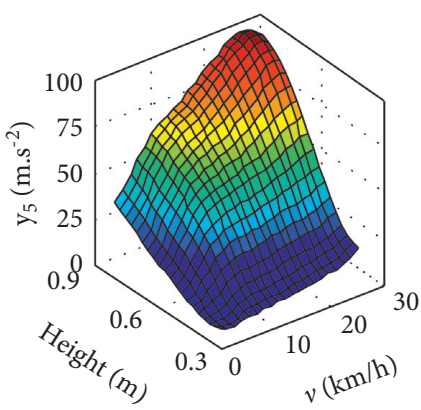

(b)

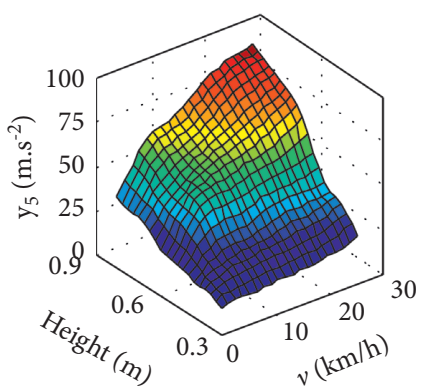

(c)

Figure 28: Approximate model of vehicle climbing vertical wall. (a) Polynomial response surface. (b) Kriging model. (c) RBF neural network.

the approximate model for the data of the sample points, as shown in Table 16. As shown in the data in the table, the RBF neural network has the highest fitting accuracy, which can more truly reflect the vibration characteristics of the vehicle crossing the trench. The RBF neural network is more suitable to replace the original multibody dynamics model than the other two models.

7.3.2. Approximate Model of Vehicle Climbing Vertical Wall. Three fitting methods such as polynomial response surface, Kriging approximation model, and RBF neural network were used to construct the relationship between the vibration response evaluation index and the two variables of the vehicle speed and vertical wall height. The approximate model obtained is shown in Figure 28.

It can be seen from Figure 28 that the vibration response increases monotonously with the increase of the vehicle speed. When the vibration response reaches the limit value due to the increase of the vehicle speed, the vehicle will be subjected to a large vibration shock, and the occupants on the vehicle will find it difficult to maintain normal operation.

Ten groups of test points were randomly selected from the sample space, and the multiple correlation coefficient $R^{2}$ 
TABLE 17: Accuracy test of approximate model in the process of vehicle climbing vertical wall.

\begin{tabular}{lccc}
\hline Test coefficient & Polynomial response surface & Kriging model & RBF neural network \\
\hline$R^{2}$ & 0.952 & 0.914 & 0.942 \\
RMSE & 0.0075 & 0.0548 & 0.0101 \\
\hline
\end{tabular}

and relative RMSE were used to test the fitting accuracy of the approximate model for the data of the sample points, as shown in Table 17. Among them, the polynomial response surface approximation model has the highest fitting accuracy.

\section{Conclusion}

In this paper, a dynamic model of the action system of a high-speed tracked vehicle is established by using the simulation analysis method, and the vibration responses of the vehicle when passing over uneven pavement, trench, and vertical wall are obtained, respectively. Furthermore, three fitting methods, namely the polynomial response surface, Kriging method, and RBF network, are used to establish the approximate model between the design variables and the objective function. The fitting accuracy judgement of the models shows the following:

(1) The RBF neural network approximate model can be used to fit the mathematical relationship between pavement roughness, vehicle speed, and vibration response.

(2) The RBF neural network approximate model boasts the highest fitting accuracy when reflecting the vibration characteristics of the vehicle crossing the trench.

(3) The polynomial response surface approximation model boasts the highest fitting accuracy when reflecting the vibration characteristics of the vehicle climbing the vertical wall.

These vibration response evaluation index and approximate models can be used to predict the maximum cross-country speed in further research. So, the results of this paper are of reference significance for the prediction and evaluation of the mobility of high-speed tracked vehicles in complex road conditions.

\section{Data Availability}

The data used to support the findings of this study are available from the corresponding author upon request.

\section{Conflicts of Interest}

The authors declare that they have no conflicts of interest.

\section{References}

[1] W. He-ping, P. Hong-xia, H. Jin-ying, and X. Hai, "Research of the crew discomfort in the vibration of vehicle," Equipment Manufactring Technology, vol. 2, pp. 28-30, 2009.
[2] C. Xin, T. Qi, S. Li, M. Jiang, and L. Hua, "A study on the analysis method of the off-road ride comfortof high mobility vehicle," Automotive Engineering, vol. 30, no. 9, pp. 736-741, 2008.

[3] S. Gao, "Research on high mobility tactic vehicle," Journal of Military Transportation University, vol. 12, no. 2, pp. 74-78, 2012.

[4] T. T. Vong, G. A. Haas, and C. L. Henry, NATO Reference Mobility Model (NRMM) Modeling of the DEMO III Experimental Unmanned Ground Vehicle (XUV), Army Research Laboratory, Aberdeen Proving Ground, MD, USA, 1999.

[5] J. D. Priddy, Improving the Traction Prediction Capabilities in the NATO Reference Mobility model(NRMM), 1999.

[6] M. Mccullough, P. Jayakumar, J. Dasch, and D Gorsich, "The Next Generation NATO Reference mobility model development," Journal of Terramechanics, vol. 73, 2017.

[7] A. Dhir and V. S. Shankhala, "Ride dynamics of high-speed tracked vehicles[J]," Vehicle System Dynamics, vol. 23, no. 3, pp. 379-409, 1994.

[8] C. Marcello, Computational Methods for the Dynamics and Stress Analysis of Multibody Track Chains, University of Illinois at Chicago, Chicago, 1998.

[9] C. Marcello, A. A. Shabana, and J. H. Choi, "Chain vibration and dynamic stress in three-dimensional multibody tracked vehicles," Multibody System Dynamics, vol. 2, no. 3, pp. 277-316, 1998.

[10] C. Scholar and N. C. Perkins, "Efficient vibration modelling of elastic vehicle track systems," Journal of Sound and Vibration, vol. 228, no. 5, pp. 1057-1078, 1999.

[11] C. Scholar and N. Perkins, Longitudinal Vibration of Elastic Vehicle Track Systems. Simulation and Modeling, pp. 60-64, SAE Transactions, Warrendale, PA, USA, 1997.

[12] B. Anon, Mechanical Vibration and Shock-Evaluation of Human Exposure to Whole-Body Vibration, International Organization for Standardization, p. 2631, ISO, Geneva, Switzerland, 1997.

[13] R. A. Lee and F. Pradko, Analytical Analysis of Human vibration. 1968 Automotive Engineering Congress and Exposition, SAE Technical Paper 680091, SAE Transactions, Warrendale, PA, USA, 1968.

[14] F. Ding, Dynamics of Tracked Armored Vehicle Suspension System, National Defence Industry Press, Beijing, China, 2004.

[15] Design and Type Approval Test Report of a High-Mobility Tracked vehicle, PLA General Armament Department, Beijing, China, 2006.

[16] J. Hong, Computational Dynamics of Multibody Systems, Higher Education Press, Beijing, China, 1999.

[17] W H-yan, W Q-long, and Q Rui, "Research on digitized modeling method of riding road of vehicle," Acta Armamentarii, vol. 37, no. No.7, pp. 1153-1160, 2016.

[18] J. Chen, MSC. ADAMS Technics and Engineering Analysis, China Water\&Power Press, Beijing, China, 2008.

[19] X. Chen, Y. Sun, and M. Jiang, "Study on modeling and analysis of cross-obstacle performance of multi-axis high mobility vehicle," Journal of Academy of Military Transportation, vol. 12, no. 2, pp. 54-57, 2010. 
[20] K. Kuhner, "Das Kraftfahreug im Gelande (Motor Vehicle and Terrain)," VDI, vol. 34, 1935.

[21] K. Zhang, Vehicle-Terramechanics, pp. 154-159, National Defense Industry Press, Beijing, China, 2002.

[22] M. Wang, Tank Driving Principle, pp. 142-147, National Defense Industry Press, Beijing, China, 1983.

[23] L. Teng, Li Liu, and M. Ling-tao, "Multi-Objective Integrated Optimization of Airfoil Based on Surrogate Model," Journal of System Simulation, vol. 22, no. 7, pp. 1604-1608, 2010.

[24] M. D. McKay, W. J. Conover, and R. J. Beckman, "A comparison of three methods for selecting values of input variables in the analysis of output from a computer code," Technometrics, vol. 21, no. 2, pp. 239-245, 1979.

[25] R. H. Myers and D. C. Montgomery, Response Surface Methodology: Process and Product Optimization Using Experiments, John Wiley \& Sons, New York, NY, USA, 2011.

[26] Q. Rui, H. Ouyang, and H. Y. Wang, "An efficient statistically equivalent reduced method on stochastic model updating," Applied Mathematical Modelling, vol. 37, no. 8, pp. 60796096, 2013.

[27] T. W. Simpson, T. M. Mauery, J. J. Korte, and M Farrokh, "Kriging models for global approximation in simulationbased multidisciplinary design optimization," AIAA Journal, vol. 39, no. 12, pp. 2233-2241, 2012.

[28] D. Bu, W. Sun, H. Yu, C Wang, and H Zhang, "Adaptive robust control based on RBF neural networks for duct cleaning robot," International Journal of Control, Automation and Systems, vol. 13, no. 2, pp. 475-487, 2015.

[29] A. Anthony, Giuma. Aircraft Multidisciplinary Design Optimization Using Design of Experiments Theory and Response Surface Modeling Methods PhD Dissertation, Virginia Polytechnic Institute, Blacksburg, VA, USA, 1997. 